Original Article

\title{
Low-Intensity Blood Flow Restriction Training Does Not Modulate Myostatin Concentration in Elderly Females
}

Farnaz Aminian

(PhD)Department of Exercise Physiology, Bojnourd Branch, Islamic Azad University, Bojnourd, Iran

Seyyed Mahmood Hejazi iD

(PhD)Department of Physical Education, Khayyam University, Mashhad, Iran

Sadegh Cheragh Birjandi

(PhD)Department of Exercise Physiology, Bojnourd Branch, Islamic Azad University, Bojnourd, Iran

Corresponding author:Mahmood

Hejazi

Email: sm.hejazi37@ gmail.com Tel: 989153155205

Address: Khayyam University,

Mashhad, Iran.

Received: $2020 / 07 / 21$

Revised: 2020/07/21

Accepted: 2019/10/21

(c) (i) \&

This work is licensed under a Creative Commons Attribution 4.0 License.

DOI: $10.29252 / \mathrm{mlj} .14 .5 .30$

\begin{abstract}
Background and Objectives: Evidence suggests that decrease in the serum concentration of myostatin (MSTN) may reduce age-related decrement in muscle mass, especially in older individuals. This study aimed at investigating the effects of 12 weeks of resistance training with and without blood flow restriction on MSTN and muscular strength (MS) of elderly women.
\end{abstract}

Methods: Thirty elderly women were randomly assigned into three groups of resistance training with blood flow restriction $(n=10)$, resistance training without blood flow restriction $(n=10)$ and control $(n=10)$. The resistance training intervention was carried out three sessions a week for 12 weeks. Body composition, MS and serum concentrations MSTN were assessed at baseline and 48-36 hours after the last training session.

Results: There was a significant time $\times$ group difference in MS following 12 weeks of exercise intervention $(P=0.001)$. However, there was no significant group and time $\times$ group difference in MSTN concentrations $(\mathrm{P}=0.2)$.

Conclusion: Low intensity BFRT does not decrease MSTN concentrations in elderly women. However, low intensity BFRT can increase MS values in these individuals.

Keywords:Myostatin, Strength, Muscle, Body Composition. 


\section{INTRODUCTION}

The aging process is associated with a significant decline in muscle mass and strength (1), which leads to various health problems including increased fatigue and decreased quality of life (2, 3). Physical activity, especially resistance training (RT), is highly recommended to preclude the negative effects of the aging process (4). It has been reported that combined upper and lower body RT would enlarge skeletal muscle mass (SMM) in older adults (3). Recently, blood flow restriction training (BFRT) with low intensities has been considered as an effective approach to increase SMM compared to traditional RT, which is performed with higher intensities (5). Recent studies reported a decrease in myostatin (MSTN) concentrations following RT $(3,5)$. Blood flow restriction increases the muscle mass by regulating several cellular pathways, including the mechanistic target of rapamycin signaling, ribosomal protein S6 kinase beta-1 and forkhead box $\mathrm{O}(6)$.

Myostatin is a member of transforming growth differentiation beta (GDF- $\beta)$ family that negatively controls muscle growth $(7,8)$. This protein is produced in the skeletal muscle tissue and acts as a muscle growth inhibitor that circulates through the bloodstream and eventually binds to activing type II receptors (9). Evidence suggests that MSTN concentration decreases following eight weeks of RT with BFRT (7) or without BFRT $(3,5$, $7)$. It has been suggested that RT could also reduce MSTN concentrations, resulting in increased SMM (9). Most studies on BFRT are short-term exercise interventions conducted on adolescents and middle-aged men or women. Given the lack of studies on the effects of BFRT on MSTN concentrations in older people, we conducted this study to evaluate the effects of 12-week of BFRT following RT on MSTN and functional strength of older women.

\section{MATERIALS AND METHODS}

Thirty elderly women took part in the present study. The inclusion criteria were age of $>60$ years and having sarcopenia confirmed based on a hand grip strength of less than 26$30 \mathrm{~kg}$, walking speed of less than $0.8 \mathrm{~m} / \mathrm{s}$ and muscle mass index less than two standard deviations from the average young population. Having regular physical activity, partaking in hormonal/mental therapies, alcohol consumption, smoking, consumption of
Supplementary smoking, consumption of supplementary drugs, and having diseases such Parkinson's disease, cardiovascular, diabetes, hypertension, obesity and kidney disease were the exclusion criteria. The criteria were investigated by a specialist physician and using the Physical Activity ReadinessQuestionnaire (PAR-Q) and a medical health/history survey.

After explaining the study objectives, the participants were familiarized with the exercise protocol and were randomly assigned into three groups of BFRT $(n=10)$, without blood flow restriction training (WBFRT; $n=$ 10) and control $(C ; n=10)$. The Participants were instructed not to alter their regular lifestyle and dietary habits during the study period. Training sessions were performed at the same time of day for all participant under the same environmental condition $\left(\sim 20^{\circ} \mathrm{C}\right.$ and $\sim 55 \%$ humidity). Height and weight were measured and body mass index was calculated by dividing body weight by the square of the height $\left(\mathrm{kg} / \mathrm{m}^{2}\right)$.

To assess lower and upper limb maximal strength, the 1-repetition maximum prediction equation $(1 \mathrm{RM}=(\mathrm{L}) /[1.0278-(\mathrm{R} \times 0.0278)]$ was used where 1RM is one repetition maximum, $\mathrm{L}$ is the external load in $\mathrm{kg}$ and $\mathrm{R}$ is the number of repetitions performed (3).

Before the main training intervention, all subjects performed one week of concurrent training, consisting of three exercise sessions. This phase allowed instruction of proper lifting techniques, familiarization with exercises and equipment, and ensured that the participants initiated the study with a comparable training base. Next, the subjects performed RT at $20 \%$ of $1 \mathrm{RM}$ for one week. The training intensity reached $25 \%$ of $1 \mathrm{RM}$ in the $4^{\text {th }}$ to $7^{\text {th }}$ week and further increased to $30 \%$ of $1 \mathrm{RM}$ in the $8^{\text {th }}$ to $12^{\text {th }}$ week. The repetitions varied from 15 to 30. The subjects performed training three days a week with 30-60 seconds rest intervals between sets and 60-120 second rest intervals between exercises. A blood pressure cuff was used to maintain blood pressure for lower body exercises and upper body exercises at 140 to $190 \mathrm{mmHg}$ and 90 to $140 \mathrm{mmHg}$, respectively. The training exercise included leg press, leg extension, leg curl, calf raise, lateral raise, chest press and lat pulldown. Participants in the BFRT group performed RT with a cuff tightened to the proximal portion of arm and femur. However, participants in the BFRT group, performed RT with the 
cuff tightened to the proximal portion of arm and leg $(3,5)$. A 30-second chair-stand test was used to estimate muscle mass (10).

Fasting blood samples $(5 \mathrm{~mL})$ were taken from the cubital vein, clotted for $15 \mathrm{~min}$ at room temperature and centrifuged at 3,000 rpm for 15 minutes. Blood samples were taken at baseline and 48-72 hours after the last training session under the same environmental condition. Before blood collection, the participants were asked to refrain from physical activity for 36 hours. The obtain serum samples were kept at $-70{ }^{\circ} \mathrm{C}$ until analysis.

Serum concentration of MSTN was measured using a commercial kit (ZB-OEH4717815 Zellbio, Germany) with sensitivity of $2.5 \mathrm{ng} / \mathrm{L}$ and intra-assay and inter-assay of less than $10 \%$ and $12 \%$, respectively.

Normality of data was verified by the ShapiroWilk test. Changes in the variables compared to baseline were examined using one-way analysis of variance (ANOVA).
A time (baseline vs. 12 weeks) $\times$ group $($ BFRT vs. WBFRT vs. C) factorial ANOVA with repeated measures was performed to determine differences between the interventions. Bonferroni post hoc test was performed when a significant treatment and treatment-by-time interaction was observed. All statistical analyses were performed using SPSS (version 24 ) at $95 \%$ confidence interval.

\section{RESULTS}

There was a significant group and time $x$ group difference in muscle strength following 12 weeks of exercise intervention $(\mathrm{P}=0.001)$. Muscle mass increased by $29.8 \%$ in the BFRT group and by $5.6 \%$ in the WBRT group. Moreover, MSTN concentration decreased by $12 \%$ in the BFRT and by $4.3 \%$ in the WBFRT group. There was no significant group and time $\times$ group difference in the MSTN concentration between the study groups $(\mathrm{P}=0.2)$.

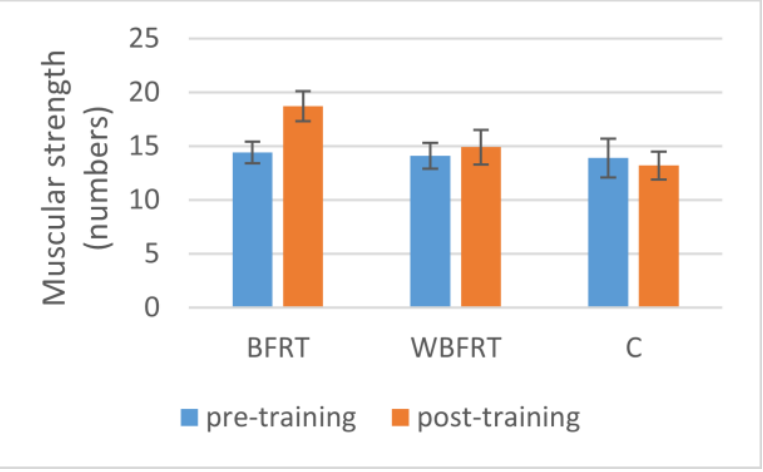

Figure 1. Effect of the intervention training on muscle strength in different study groups

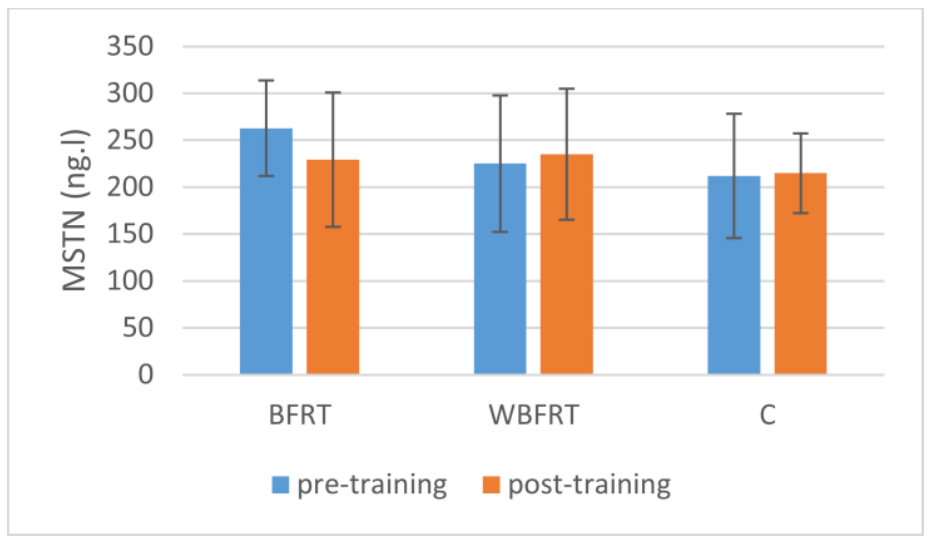

Figure 2. Effect of the intervention training on MSTN concentration in different study groups 


\section{DISCUSSION}

We observed a considerable increase in muscle strength and a slight decrease in MSTN concentrations following 12 weeks of RT with BFRT in elderly women. In agreement with our findings, a previous study reported that 12 weeks of BFRT in elderly men and women increased MS (11). Another study also reported that 12 sessions of lowintensity BFRT increased quadriceps strength in healthy young men (12). It has been reported that muscle strength is highly dependent on type II muscle fibers rather than type I muscle fibers due to oxygen deficiency and lactate accumulation following BFRT (13). This may subsequently alter muscle strength (6). Another potential mechanism responsible for the increased muscle strength may be heat shock proteins, which strongly decrease the most important protein degradation pathway, ubiquitin proteasome (14). However, this pathway can be inhibited by increased HSP72 level after periodised training intervention.

We found no significant time $\times$ group difference in MSTN concentrations. A cross sectional study on young, middle-aged and older men and women proposed that the agerelated increase in serum MSTN concentrations is highest in 'physically frail' older women and reversely correlated with SMM (15). We did not detect a significant decrease in MSTN concentration after 12 weeks of RT. This may be due to low pressure of cuff as well as high volume of our RT protocol. It has been shown that RT with high volume and low intensity might increase blood glucocorticoid concentrations, which is positively correlated with MSTN rise (16). Inconsistent with our results, a study reported that eight weeks of lower body RT with BFRT can significantly decrease MSTN (5). Moreover, energy deficiency during RT can increase tuberous sclerosis complex 2 protein levels. This in turn raises forkhead box $\mathrm{O}$ protein concentrations, which subsequently increases MSTN concentrations (6).

\section{CONCLUSIONS}

Based on our findings, BFRT can be utilized as an effective approach to reduce strength loss during aging. We recommend using higher intensity BFRT as well as lower RT volume to further decrease MSTN concentration in older individuals.

\section{ACKNOWLEDGMENTS}

We express our upmost gratitude to all study participants.

\section{CONFLICT OF INTEREST}

The authors declare that there is no conflict of interest.

\section{REFERENCES}

1.Larsson L, Degens H, Li M, Salviati L, Lee Yi, Thompson W, et al. Sarcopenia: aging-related loss of muscle mass and function. Physiol Rev. 2019; 99(1): 427-511.doi: 10.1152/physrev.00061.2017.

2.Hunter GR, McCarthy JP, Bamman MM. Effects of resistance training on older adults. Sports Med. 2004; 34(5): 329-48.doi: 10.2165/00007256-200434050-00005.

3.Bagheri R, Rashidlamir A, Motevalli MS, Elliott BT, Mehrabani J, Wong A. Effects of upper-body, lower-body, or combined resistance training on the ratio of follistatin and myostatin in middle-aged men. Eur J Appl Physiol. 2019; 119(9): 1921-1931. doi: 10.1007/s00421-019-04180-z.

4.Hakkinen K, Pakarinen A, Kraemer WJ, Newton RU, Alen M. Basal concentrations and acute responses of serum hormones and strength development during heavy resistance training in middle-aged and elderly men and women. J Gerontol A Biol Sci Med Sci. 2000; 55(2): B95-105.doi: 10.1093/gerona/55.2.b95.

5.Bagheri R, Rashidlamir A, Attarzadeh Hosseini SR. Effect of Resistance Training with Blood Flow Restriction onfollistatin to myostatin Ratio, Body Composition and Anaerobic Power of Trained-Volleyball Players. Mljgoums. 2018; 12(6): 28-33. DOI: $10.29252 / \mathrm{mlj} .12 .6 .28$.

6.Laplante M, Sabatini DM. mTOR signaling at a glance. Journal of cell science. 2009; 122(20): 3589-94. doi: 10.1242/jcs.051011.

7.Laurentino GC, Ugrinowitsch C, Roschel H, Aoki MS, Soares AG, Neves Jr M, et al. Strength training with blood flow restriction diminishes myostatin gene expression. Med Sci Sports Exerc. 2012; 44(3): 406-12.doi: 10.1249/MSS.0b013e318233b4bc.

8.Mafi F, Biglari S, Ghardashi Afousi A, Gaeini AA. Improvement in Skeletal Muscle Strength and Plasma Levels of Follistatin and Myostatin Induced by an 8-Week Resistance Training and Epicatechin Supplementation in Sarcopenic Older Adults. J Aging Phys Act. 2019; 27(3): 384-391.doi: 10.1123/japa.2017-0389.

9.Negaresh R, Ranjbar R, Baker JS, Habibi A, Mokhtarzade M, Gharibvand MM, et al. Skeletal muscle hypertrophy, insulin-like growth factor 1, myostatin and follistatin in healthy and sarcopenic elderly men: The effect of whole-body resistance training. Int J Prev Med. 2019;10:29.doi: 10.4103/ijpvm.IJPVM_310_17. eCollection 2019.

10.Jones CJ, Rikli RE, Beam WC. A 30-s chair-stand test as a measure of lower body strength in community-residing older adults. Res Q Exerc Sport. 1999 Jun;70(2):113-9.doi: 10.1080/02701367.1999.10608028

11.Vechin FC, Libardi CA, Conceição MS, Damas FR, Lixandrão ME, Berton RP, et al. Comparisons between lowintensity resistance training with blood flow restriction and high-intensity resistance training on quadriceps muscle mass and strength in elderly. Randomized Controlled Trial J Strength Cond Res. 2015; 29(4): 1071-6.doi: 10.1519/JSC.0000000000000703.

12.Fujita T, WF B, Kurita K, Sato Y, Abe T. Increased muscle volume and strength following six days of low-intensity resistance training with restricted muscle blood flow. International Journal of KAATSU Training Research. 2008; 4(1): 1-8. DOI: 10.3806/ijktr.4.1.

13.Lundberg G, Olofsson P, Ungerstedt U, Jansson E, Sundberg C. Lactate concentrations in human skeletal muscle biopsy, microdialysate and venous blood during dynamic exercise under blood flow restriction. Pflugers Arch. 2002; 443(3): 458-65.doi: $10.1007 / \mathrm{s} 004240100706$ 
14.Meriin AB, Gabai VL, Yaglom J, Shifrin VI, Sherman MY. Proteasome inhibitors activate stress kinases and induce Hsp 72 Diverse effects on apoptosis. Journal of Biological Chemistry. 1998; 273(11): 6373-9.

15. Yarasheski K, Bhasin S, Sinha-Hikim I, Pak-Loduca J, Gonzalez-Cadavid N. Serum myostatin-immunoreactive protein is increased in 60-92 year old women and men with muscle wasting. J Nutr Health Aging. 2002; 6(5): 343-8.
16. Gilson H, Schakman O, Combaret L, Lause P, Grobet L, Attaix D, et al. Myostatin gene deletion prevents glucocorticoid-induced muscle atrophy. Endocrinology. 2007; 148(1): 452-60.doi: 10.1210/en.2006-0539.

\section{How to Cite:}

This paper should be cited as: F Aminian, S M Hejazi, S Cheragh Birjandi. [Low-Intensity Blood Flow Restriction Training Does Not Modulate Myostatin Concentration in Elderly Females]. mljgoums. 2020; 14(5):30-34 . DOI: 10.29252/mlj.14.5.30 